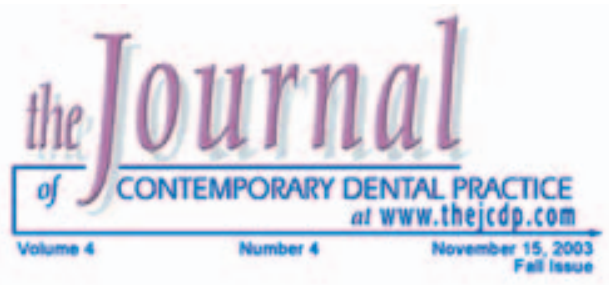

\title{
Prediction of the Size of Un-erupted Permanent Cuspids and Bicuspids in a Saudi Sample: A Pilot Study
}

\author{
Hayder A. Hashim, BDS, MSc; Thakib A. Al-Shalan, BDS, MS, PhD
}

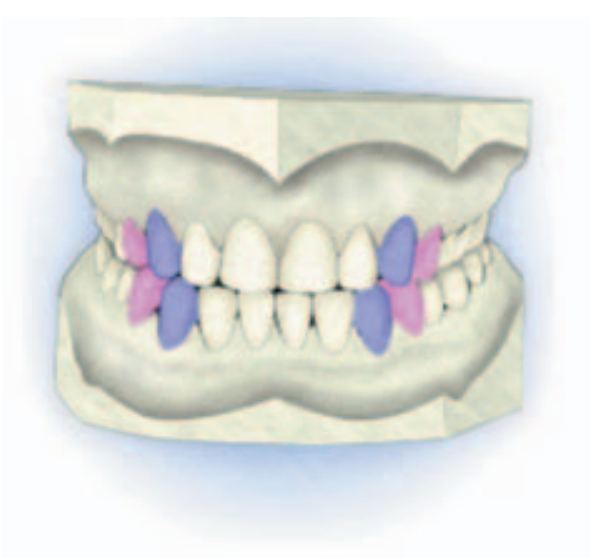

\begin{abstract}
The purpose of this study was to produce an estimated equation for the prediction of unerupted cuspids and bicuspids for the Saudi population. In this study, dental casts of 65 Saudi subjects (37 males and 28 females) were used. The subjects' age ranged from 18 to 25 years. The mesiodistal width of all permanent teeth was measured. The data was subjected to regression analysis. Results showed the Tanaka and Johnston equations overestimate the predicted tooth width of the un-erupted cuspids and bicuspids in Saudis. Results showed the predicted tooth width of Saudis (males and females) is closer to the $50 \%$ level of confidence in Moyer's chart. Multiple regression equations were estimated including the sex factor. Accordingly, two equations were estimated for the prediction of the tooth width of the un-erupted cuspids and bicuspids for the Saudi males and females. Based on the results, it can be concluded the $50 \%$ data is more accurate than the commonly used percentage Moyer's table (75\%) when both sexes are combined. Further studies are needed to confirm the findings of this study.

Keywords: Predicted tooth size, Moyer's prediction probability table

Citation: Hashim HA, Al-Shalan TA. Prediction of the Size of Un-erupted Permanent Cuspids and Bicuspids in a Saudi Sample: A Pilot Study. J Contemp Dent Pract 2003 November;(4)4:040-053.
\end{abstract}

(c) Seer Publishing 


\section{Introduction}

Orthodontists are faced with daily progress in the field of clinical orthodontics. The advances in the diagnostic phase of treatment have been plentiful. The dental casts are still considered a vital diagnostic tool. ${ }^{1}$ From the dental cast, one can analyze tooth size and shape, alignment and rotations of the teeth, presence or absence of teeth, arch form and symmetry, and arch width and occlusal relationship.

A significant variation in the occlusal harmony may lead to malocclusion and difficulties in obtaining an occlusion with optimal overjet, overbite, and class I canine and molar relationship. One possible reason for malocclusion is the tooth size. Although the natural teeth match very well in most individuals, approximately $5 \%$ of the populations have some degree of discrepancy among the sizes of individual teeth. ${ }^{3}$

The term tooth size denotes the mesiodistal width of a tooth. Various terms have been used in the literature to represent tooth size including tooth diameter $^{4,5,6}$, the breadth ${ }^{7}$, and tooth width. ${ }^{8}$

Like all other biological forms, teeth are present in different sizes and shapes. Variation in the size and shape of teeth are predominantly genetically determined. ${ }^{9,10}$ The genetic basis for this variation is best explained by the polygenic model of inheritance. Lundström ${ }^{7}$ compared 97 pairs of like-sex monozygotic and dizygotic twins. He found a stronger correlation in mesiodistal tooth size between monozygotic twins and concluded the tooth size is determined to a large extent by genetic factors.

Several methods were introduced and used to predict the sizes of the un-erupted teeth. ${ }^{2,11,12,13}$ The most common method among these is Moyer's analysis. ${ }^{2}$ Moyer established probability tables to obtain the predicted space required to align the permanent upper and lower canines, as well as the first and second premolars, using the sum of the four lower permanent incisors. Further, Tanaka and Johnston ${ }^{12}$ presented prediction equations which give relatively similar values to Moyer's prediction probability table. These equations are widely used currently.

Al-Khadra ${ }^{14}$ carried out a study in one hundred Saudi orthodontic patients randomly selected from the orthodontic clinic in the College of Dentistry at King Saud University (CDKSU). Following specific criteria, only 34 patients were found to fulfill those criteria. Measurements of mesiodistal widths of permanent mandibular incisors and all canines and premolars were performed in the dental casts of these patients by two examiners. Al-Khadra found the 35\% level was a more accurate determinant than the commonly used $75 \%$ confidence level. Further, he found the Tanaka and Johnston prediction equation overestimated the size of buccal segments in the Saudi population sample. He concluded the data illustrates the limitations of these methods when applied to a sample population of other than European descent. Finally, he introduced two linear regression equations for tooth size prediction in Saudi Arabia.

Since the Al-Khadra study was the only one carried out among Saudis, the intention of this study is to formulate an equation for the prediction of the un-erupted cuspid and bicuspids in Saudis and to compare the results with other previous studies.

\section{Material and Methods}

For male subjects, a total of 1500 military training officers in King Abdulaziz Military Academy (KAMA) were examined clinically in the dental clinic in KAMA. For the female subjects, female dental students (third, fourth, and fifth year students) were also examined. For both male and female subjects, dental casts were taken. A total of 65 subjects ( 37 males and 28 females) were selected based on the following criteria:

\section{The Criteria for Sample Selection}

- All subjects were native Saudi.

- Ages ranged from 18 to 25 years.

- Class I molar and canine relationship with normal overjet and overbite.

- Subjects were free from crowding, spacing, and rotation of the teeth, and had no restorative treatments other than class I restorations. 
- Presence of fully erupted permanent teeth from the right first molar to the left first molar of both the maxillary and mandibular arches.

- None of the subjects gave a history of previous orthodontic treatment.

- Subjects with congenitally missing teeth, extracted teeth, questionable articulation, malformed teeth, broken or chipped teeth, or carious lesion that could affect the mesiodistal tooth width were not included in the sample.

\section{Methods}

Impressions for both jaws of the subjects were taken using irreversible hyrocolloid impression materials (Kromopan alginate impression, Italy). The dental casts were allowed to dry on a table for one hour and numbered for identification. The casts were trimmed and prepared without being soaped.

\section{Dental Study Cast Measurements}

The measurements were made directly on the unsoaped dental casts. One operator took all measurements under natural and neon light. An electronic digital cali-

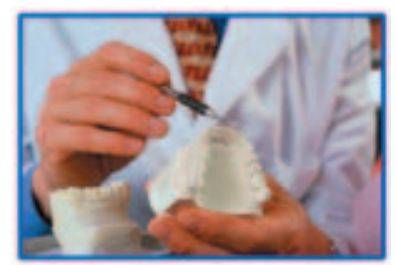
per (Digimatic calipers, Mitutoyo, U.K.) was used for measuring the mesiodistal tooth width from the right permanent first molar to the left permanent first molar for both upper and lower jaws.

The procedure for measuring the mesiodistal tooth width was performed as described by Hunter and Priest. ${ }^{5}$ The caliper beaks were inserted from the buccal (labial), and held occlusally parallel to the long axis of the tooth. The beaks were then closed until gentle contact with the contact points of the tooth was made. The measurements included the mesiodistal width of all the twelve maxillary and mandibular teeth from the right first permanent molar to the left first permanent molar. The measurements were made as carefully as possible to avoid any damage to the casts.

In the present study, the error of the method was determined by repeating the measurements for twenty pairs of dental casts with one-week intervals. The same operator did all measurements.
Three statistical tests: Dahlberg's method ${ }^{15}$, Pearson's correlation coefficient, and t-test for paired samples were used for analyzing the error of the method. Regression equations were estimated for the prediction of tooth size in Saudis. The estimated regression equations take the form:

$\mathbf{Y}=\mathbf{A}+\mathbf{B}(\mathbf{X})$ Where:

$\mathbf{Y}=$ The predicted size of the cuspids, and first and second bicuspids in one quadrant in millimeters.

$\mathbf{X}=$ The measured width of the four permanent mandibular incisors in millimeters.

A \& B are the estimated regression constant and regression coefficient, respectively.

Further, multiple regression equations were estimated which included the sex factor. They take the form:

$\mathbf{Y}=\mathbf{A}+\mathbf{B}\left(\mathbf{X}_{1}\right)+\mathbf{C}\left(\mathbf{X}_{2}\right)$ Where:

$\mathbf{X}_{1}$ is the measured width of the four permanent mandibular incisors in millimeters.

$\mathbf{X}_{2}$ is a dummy variable which takes the value 1 for male and 0 for female.

B \& C are partial regression coefficients.

Significant differences were observed when the sex factor was included in both jaws.

\section{Results}

Table 1 shows the error of the method for the individual tooth width.

Dahlberg's method revealed the lower left second premolar exhibited the highest error $(0.32 \mathrm{~mm})$, whereas the upper right first molar demonstrated the lowest error $(0.05 \mathrm{~mm})$.

Pearson's correlation coefficient indicated a high correlation between the readings for all individual teeth. The lower right central incisor showed the least correlation $(r=0.51)$.

The t-test for paired samples showed no statistically significant differences could be observed between the two readings of the individual tooth width for all cases. 
Table 1. Error of the method for individual tooth width by Dahlberg's method (DM). Pearson's correlation coefficient ( $r$ ), the dependent paired t-test ( $(t)$, and level of significance $(P)$. All measurements are in millimeters $(\mathrm{N}=20$ casts $)$.

\begin{tabular}{|c|c|c|c|c|c|c|c|c|c|}
\hline \multirow{2}{*}{\multicolumn{2}{|c|}{ Pairs }} & \multicolumn{4}{|c|}{ Right side } & \multicolumn{4}{|c|}{ Left side } \\
\hline & & \multirow{2}{*}{$\begin{array}{l}\text { D. M. } \\
0.06\end{array}$} & \multirow{2}{*}{$\begin{array}{c}\mathbf{r} \\
0.98\end{array}$} & \multirow{2}{*}{$\frac{t}{1.79}$} & \multirow{2}{*}{$\begin{array}{c}P \\
>0.05\end{array}$} & \multirow{2}{*}{$\begin{array}{l}\text { D.M. } \\
0.09\end{array}$} & \multirow{2}{*}{$\begin{array}{c}r \\
0.95\end{array}$} & \multirow{2}{*}{$\frac{t}{0.64}$} & \multirow{2}{*}{$\begin{array}{c}\mathbf{P} \\
>0.0 \text { s }\end{array}$} \\
\hline \multirow{6}{*}{$\begin{array}{l}\text { Upper } \\
\text { Jaw }\end{array}$} & Central incisor & & & & & & & & \\
\hline & Lateral incisor & 0.25 & 0.71 & 0.52 & $>0.05$ & 0.08 & 0.97 & 0.66 & $>0.05$ \\
\hline & Canine & 0.25 & 0.71 & -0.10 & $>0.05$ & 0.20 & 0.79 & -1.30 & $>0.05$ \\
\hline & First premolar & 0.14 & 0.91 & 0.65 & $>0.05$ & 0.13 & 0.89 & 0.03 & $>0.05$ \\
\hline & Second premolar & 0.20 & 0.86 & -0.60 & $>0.05$ & 0.24 & 0.80 & 0.22 & $>0.05$ \\
\hline & First molar & 0.05 & 0.99 & 1.89 & $>0.05$ & 0.14 & 0.94 & 0.56 & $>0.05$ \\
\hline \multirow{6}{*}{$\begin{array}{l}\text { Lower } \\
\text { Jaw }\end{array}$} & Central incisor & 0.12 & 0.51 & -1.10 & $>0.05$ & 0.22 & 0.83 & -1.70 & $>0.05$ \\
\hline & Lateral incisor & 0.12 & 0.91 & -0.90 & $>0.05$ & 0.13 & 0.87 & -1.00 & $>0.05$ \\
\hline & Canine & 0.14 & 0.93 & -0.10 & $>0.05$ & 0.11 & 0.92 & 0.74 & $>0.05$ \\
\hline & First premolar & 0.10 & 0.91 & -1.10 & $>0.05$ & 0.16 & 0.96 & 0.63 & $>0.05$ \\
\hline & Second premolar & 0.30 & 0.72 & 1.37 & $>0.05$ & 0.32 & 0.63 & -0.10 & $>0.05$ \\
\hline & First molar & 0.24 & 0.95 & 0.00 & $>0.05$ & 0.09 & 0.84 & -1.40 & $>0.05$ \\
\hline
\end{tabular}

Table 2. Predicted tooth width of mandibular cuspids and bicuspids (males and females combined).

\begin{tabular}{|c|c|c|c|c|c|c|}
\hline \multirow{2}{*}{$\begin{array}{l}\text { Sum of Mandibular } \\
\text { Incisors (mm) }\end{array}$} & \multirow{2}{*}{$\begin{array}{c}\text { Present Study } \\
n=65\end{array}$} & \multicolumn{3}{|c|}{$\begin{array}{l}\text { Moyer's } \\
\text { Prediction }\end{array}$} & \multirow{2}{*}{$\begin{array}{l}\text { Tanaka and } \\
\text { Johnston }\end{array}$} & \multirow{2}{*}{$\begin{array}{l}\text { Al-Khadra Saudi } \\
\text { Sample n=34 }\end{array}$} \\
\hline & & $35 \%$ & $50 \% *$ & $65 \%$ & & \\
\hline 19.5 & 19.3 & 19.0 & $19.4^{*}$ & 19.8 & 20.3 & 19.3 \\
\hline 20.0 & 19.6 & 19.3 & $19.7^{*}$ & 20.1 & 20.5 & 19.6 \\
\hline 20.5 & 19.9 & 19.6 & $20.0^{*}$ & 20.4 & 20.8 & 19.9 \\
\hline 21.0 & 20.2 & 19.9 & $20.3^{*}$ & 20.7 & 21.0 & 20.2 \\
\hline 21.5 & 20.5 & 20.2 & $20.6^{*}$ & 21.0 & 21.3 & 20.4 \\
\hline 22.0 & 20.8 & 20.5 & $20.9^{*}$ & 21.3 & 21.5 & 20.7 \\
\hline 22.5 & 21.1 & 20.8 & $21.2^{*}$ & 21.6 & 21.8 & 21.0 \\
\hline 23.0 & 21.4 & 21.1 & $21.5^{*}$ & 21.9 & 22.0 & 21.3 \\
\hline 23.5 & 21.7 & 21.4 & $21.8^{\circ}$ & 22.2 & 22.3 & 21.5 \\
\hline 24.0 & 22.0 & 21.7 & $22.1^{*}$ & 22.5 & 22.5 & 21.8 \\
\hline 24.5 & 22.3 & 22.0 & $22.4^{*}$ & 22.8 & 22.8 & 22.1 \\
\hline 25.0 & 22.6 & 22.3 & $22.7^{*}$ & 23.1 & 23.0 & 22.4 \\
\hline
\end{tabular}

Note: Asterisks indicate that results are similar to Moyer's Probability Tables. 2

" $=$ more than one level close to our results 
When the data is subjected to the regression analysis, the following equations were obtained for the prediction of the size of the maxillary and mandibular cuspids and first and second bicuspids in Saudis.

\section{Estimated equations for both males and females combined:}

i) Maxillary $Y=9.291+0.546(X)$

ii) Mandibular $Y=7.606+0.601(\mathrm{X})$

\section{Estimated equations for males:}

i) Maxillary $Y=9.731+0.536(X)$

ii) Mandibular $Y=7.976+0.593(X)$

Estimated equations for the females:

v) Maxillary $Y=9.229+0.536(X)$

vi) Mandibular $Y=7.555+0.593(\mathrm{X})$

Where:

$\mathbf{Y}=$ The mesiodistal tooth width of the cuspids and first and second bicuspids in one buccal segment in millimeters.

$\mathbf{X}=$ The measured width of the four permanent mandibular incisors in millimeters.

Tables 2 and 3 show the results of the present study compared to Moyer's prediction table at $35 \%$, 50\%, and 65\%; Tanaka and Johnston equations; and Al-Khadra's results respectively for the mandibular and maxillary cuspids and bicuspids.

A significant difference is observed when the results of the present study are compared with the Tanaka and Johnston equations. The difference is greater when the width of the lower incisors is small. On the other hand, the values of the predicted width of the cuspids, first and second bicuspids in both jaws obtained by Tanaka and Johnston equations at all sizes is greater than the result of the present study. No significant difference is observed between the results of the current study and the AL-Khadra study.

The results illustrate the actual measurements of the present study are much closer to the Moyer's table at the $50 \%$ confidence level in both maxillary and mandibular buccal segments.

Tables 4 and 5 exhibit the results of the present study in the upper jaw for the males and females compared to Moyer's prediction at $65 \%, 75 \%$, and
$85 \%$ level of confidence. The results indicate the actual measurements are relatively closer to the $75 \%$ level of confidence for males, whereas for the females two confidence levels $65 \%$ and $75 \%$ are observed.

Tables 6 and 7 demonstrate the results of the current investigation in the lower jaw for the males and females compared to Moyer's prediction at $50 \%, 65 \%$, and $75 \%$ level of confidence. The results indicate the actual measurements for males are relatively closer to the $65 \%$ level of confidence, whereas for the females two confidence levels $65 \%$ and $75 \%$ are noticed.

\section{Discussion}

The mesiodistal tooth size of the maxillary and mandibular arch must relate to each other in order to obtain an optimal occlusion at the completion of the orthodontic treatment. ${ }^{16}$ If a patient has significant tooth size discrepancy, orthodontic alignment into optimal occlusion may not be possible. ${ }^{17}$ Crosby and Alexander ${ }^{18}$ and Freeman et al. ${ }^{19}$ reported a large percentage of orthodontic patients possess significant tooth size discrepancies. Therefore, orthodontists should be aware of the existence of these discrepancies before beginning orthodontic treatment. The treatment alternatives of tooth size discrepancies include restoration of relatively small teeth, interproximal stripping of relatively large teeth, modification of crown angulation or inclination and extraction. ${ }^{20}$

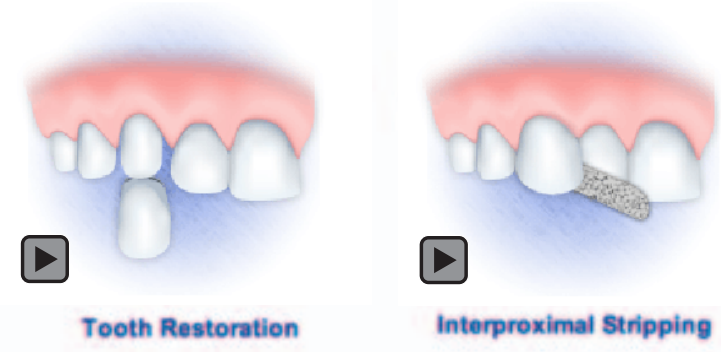

Bolton $^{21}$ and Tuverson ${ }^{22}$ indicated that overbite, overjet, and interincisal angle might influence ideal tooth size relationships. However, no definite conclusions have been drawn as to the effect that overbite, overjet, and interincisal angle have on the accuracy of tooth size analysis.

A simple linear regression equation was estimated and used for the prediction of the tooth width of the permanent cuspids and bicuspids 
Table 3. Predicted tooth width of maxillary cuspids and bicuspids (males and females combined).

\begin{tabular}{|c|c|c|c|c|c|c|}
\hline \multirow{2}{*}{$\begin{array}{l}\text { Sum of Mandibular } \\
\text { Incisors ( } \mathrm{mm})\end{array}$} & \multirow{2}{*}{$\begin{array}{l}\text { Present Study } n= \\
65\end{array}$} & \multicolumn{3}{|c|}{$\begin{array}{l}\text { Moyer's } \\
\text { Prediction }\end{array}$} & \multirow{2}{*}{$\begin{array}{c}\text { Tanaka and } \\
\text { Johnston }\end{array}$} & \multirow{2}{*}{$\begin{array}{l}\text { Al-Khadra Saud } \\
\text { Sample } n=34\end{array}$} \\
\hline & & $35 \%$ & $50 \% *$ & $65 \%$ & & \\
\hline 19.5 & 19.9 & 19.6 & $20.0^{*}$ & 20.8 & 20.8 & 19.5 \\
\hline 20.0 & 20.2 & 19.9 & $20.3^{*}$ & 20.6 & 21.0 & 19.8 \\
\hline 20.5 & 20.5 & 20.2 & $20.6^{*}$ & 20.9 & 21.3 & 20.1 \\
\hline 21.0 & 20.8 & 20.5 & $20.8^{*}$ & 21.2 & 21.5 & 20.4 \\
\hline 21.5 & 21.0 & 20.8 & $21.1^{*}$ & 21.5 & 21.8 & 20.7 \\
\hline 22.0 & 21.3 & 21.0 & $21.4^{*}$ & 21.8 & 22.0 & 21.1 \\
\hline 22.5 & 21.6 & 21.3 & $21.7^{*}$ & 22.0 & 22.2 & 21.4 \\
\hline 23.0 & 21.9 & 21.6 & $21.9^{*}$ & 22.3 & 22.5 & 21.7 \\
\hline 23.5 & 22.1 & 21.9 & $22.2^{*}$ & 22.6 & 22.8 & 22.0 \\
\hline 24.0 & 22.4 & 22.1 & $22.5^{*}$ & 22.8 & 23.0 & 22.3 \\
\hline 24.5 & 22.7 & 22.4 & $22.8^{\circ}$ & 23.1 & 23.1 & 22.6 \\
\hline 25.0 & 22.9 & 22.7 & $23.0^{\circ}$ & 23.4 & 23.5 & 23.0 \\
\hline
\end{tabular}

Note: Asterisks indicate that results are similar to Moyer's Probability Tables. ${ }^{2}$

$*=$ more than one level close to our results

Table 4. Predicted tooth width of maxillary cuspids and bicuspids in males.

\begin{tabular}{|c|c|c|c|c|}
\hline \multirow{2}{*}{$\begin{array}{c}\text { Sum of Mandibular } \\
\text { Incisors }(\mathbf{m m})\end{array}$} & $\begin{array}{c}\text { Present Study } \\
\mathbf{n = 3 7}\end{array}$ & \multicolumn{3}{|c|}{ Moyer's Prediction } \\
\cline { 4 - 5 } & 20.2 & 20.0 & $20.3^{*}$ & 20.6 \\
\hline 19.5 & 20.5 & 20.3 & $20.5^{*}$ & 20.9 \\
\hline 20.0 & 20.7 & 20.5 & $20.8^{*}$ & 21.1 \\
\hline 20.5 & 21.0 & 20.8 & $21.0^{*}$ & 21.3 \\
\hline 21.0 & 21.3 & 21.0 & $21.3^{*}$ & 21.6 \\
\hline 21.5 & 21.5 & 21.3 & $21.5^{*}$ & 21.8 \\
\hline 22.0 & 21.8 & 21.5 & $21.8^{*}$ & 22.1 \\
\hline 22.5 & 22.1 & 21.8 & $22.0^{*}$ & 22.3 \\
\hline 23.0 & 22.3 & 22.0 & $22.3^{*}$ & 22.6 \\
\hline 23.5 & 22.6 & 22.3 & $22.5^{*}$ & 22.8 \\
\hline 24.0 & 22.9 & 22.5 & $22.8^{*}$ & 23.1 \\
\hline 24.5 & 23.1 & 22.8 & $23.0^{*}$ & 23.3 \\
\hline 25.0 & & & & \\
\hline & & & & \\
\hline
\end{tabular}

Note: Asterisks indicate that results are similar to Moyer's Probability Tables. 2

$*=$ more than one level close to our results 
Table 5. Predicted tooth width of maxillary cuspids and bicuspids in females.

\begin{tabular}{|c|c|c|c|c|}
\hline \multirow{2}{*}{$\begin{array}{c}\text { Sum of Mandibular } \\
\text { Incisors (mm) }\end{array}$} & $\begin{array}{c}\text { Present Study } \\
\mathbf{n = 2 8}\end{array}$ & \multicolumn{3}{|c|}{ Moyer's Prediction } \\
\cline { 4 - 5 } & 19.7 & $\mathbf{6 5 \% *}$ & $\mathbf{7 5 \% * *}$ & $\mathbf{8 5 \%}$ \\
\hline 19.5 & 19.9 & $20.1^{*}$ & 20.4 & 20.8 \\
\hline 20.0 & 20.2 & $20.3^{*}$ & 20.5 & 20.9 \\
\hline 20.5 & 20.5 & $20.5^{*}$ & 20.8 & 21.0 \\
\hline 21.0 & 20.8 & $20.6^{*}$ & 20.9 & 21.3 \\
\hline 21.5 & 21.0 & 20.7 & $21.0^{* *}$ & 21.4 \\
\hline 22.0 & 21.3 & 20.9 & $21.2^{* *}$ & 21.5 \\
\hline 22.5 & 21.6 & 21.0 & $21.3^{* *}$ & 21.7 \\
\hline 23.0 & 21.8 & 21.2 & $21.5^{* *}$ & 21.8 \\
\hline 23.5 & 22.1 & 21.3 & $21.3^{* *}$ & 22.0 \\
\hline 24.0 & 22.4 & 21.4 & $21.8^{* *}$ & 22.1 \\
\hline 24.5 & 22.6 & 21.6 & $21.9^{* *}$ & 22.3 \\
\hline 25.0 & & & & \\
\hline & 25 & & & \\
\hline
\end{tabular}

Note: Asterisks indioate that results are similar to Moyers Probability Tables. 2 $*=$ more than one level close to our results

$\mathrm{m}=$ more than two level close to our results

Table 6. Predicted tooth width of mandibular cuspids and bicuspids in males.

\begin{tabular}{|c|c|c|c|c|}
\hline \multirow{2}{*}{$\begin{array}{l}\text { Sum of Mandibular } \\
\text { Incisors (mm) }\end{array}$} & \multirow{2}{*}{$\begin{array}{c}\text { Present Study } \\
\qquad=37\end{array}$} & \multicolumn{3}{|c|}{ Moyer's Prediction } \\
\hline & & $65 \% *$ & $75 \%$ & $50 \%$ \\
\hline 19.5 & 19.5 & $20.0^{*}$ & 20.4 & 19.5 \\
\hline 20.0 & 19.8 & $20.2^{*}$ & 20.6 & 19.7 \\
\hline 20.5 & 20.1 & $20.4^{*}$ & 20.8 & 20.0 \\
\hline 21.0 & 20.4 & $20.6^{*}$ & 21.0 & 20.2 \\
\hline 21.5 & 20.7 & $20.9^{*}$ & 21.2 & 20.4 \\
\hline 22.0 & 21.0 & $21.1^{*}$ & 21.4 & 20.6 \\
\hline 22.5 & 21.3 & $21.3^{*}$ & 21.6 & 20.9 \\
\hline 23.0 & 21.6 & $21.5^{*}$ & 21.9 & 21.1 \\
\hline 23.5 & 21.9 & $21.8^{\circ}$ & 22.1 & 21.3 \\
\hline 24.0 & 22.2 & 22.0 & $22.3^{*}$ & 21.5 \\
\hline 24.5 & 22.5 & 22.2 & $22.5^{*}$ & 21.7 \\
\hline 25.0 & 22.8 & 22.4 & $22.8^{\circ}$ & 22.0 \\
\hline
\end{tabular}

Note: Asterisks indicate that results are similar to Moyer's Probability Tables. 2

" = more than one level close to our results 
Table 7. Predicted tooth width of mandibular cuspids and bicuspids in females.

\begin{tabular}{|c|c|c|c|c|}
\hline $\begin{array}{c}\text { Sum of Mandibular } \\
\text { Incisors (mm) }\end{array}$ & $\begin{array}{c}\text { Present Study } \\
\mathbf{n = 2 8}\end{array}$ & \multicolumn{3}{|c|}{ Moyer's Prediction } \\
\cline { 5 - 5 } & 19.1 & $19 \%^{*}$ & $\mathbf{7 5 \%}$ & $\mathbf{5 0 \%}$ \\
\hline 19.5 & 19.4 & $19.2^{*}$ & 19.6 & 18.7 \\
\hline 20.0 & 19.7 & $19.7^{*}$ & 20.1 & 19.0 \\
\hline 20.5 & 20.0 & $20.0^{*}$ & 20.3 & 19.5 \\
\hline 21.0 & 20.3 & $20.2^{*}$ & 20.6 & 19.8 \\
\hline 21.5 & 20.6 & $20.5^{*}$ & 20.8 & 20.0 \\
\hline 22.0 & 20.9 & $20.7^{*}$ & 21.1 & 20.3 \\
\hline 22.5 & 21.2 & 21.0 & $21.3^{* *}$ & 20.5 \\
\hline 23.0 & 21.5 & 21.3 & $21.6^{* *}$ & 20.8 \\
\hline 23.5 & 21.8 & 21.5 & $21.9^{* *}$ & 21.1 \\
\hline 24.0 & 22.1 & 21.8 & $22.1^{* *}$ & 21.3 \\
\hline 24.5 & 22.4 & 22.1 & $22.4^{* *}$ & 21.6 \\
\hline 25.0 & & & & \\
\hline & & & & \\
\hline
\end{tabular}

Note: Asterisks indicate that results are similat to Moyer's Probability Tables. 2

$n=$ more than one level close to our results

$\mathrm{m}=$ more than tho levels close to our results

for the Saudis. The result revealed the $50 \%$ level was a more accurate determinant of the cuspid and bicuspids than the commonly used $75 \%$ level. This result disagreed with the result reported by Al-Khadra for Saudi subjects which suggested the $35 \%$ level is an accurate determinant. This disagreement may be due to the fact Al-Khadra did not consider the $50 \%$ level of Moyer's prediction which seems to also follow his predictions closely. Moreover, he used a scatter diagram instead of using the true values obtained from the suggested equations. In fact, a comparison between the predicted tooth width of the cuspids and bicuspids of the present study and the values obtained using Al-Khadra equations revealed no significant difference. Accordingly it may be claimed both the results of the present study and Al-Khadra's equations seem to support the $50 \%$ level in the mandibular arch more than the maxillary one. Al-Khadra's study found the $35 \%$ level values in Moyer's chart are closer to his result, while in the present study the 50\% level values in Moyer's chart are more accurate. This indicates if we use the Moyer's chart for the mandibular arch, the true value falls between the $35 \%$ and $50 \%$ level of confidence. Hence, it is advisable to directly use the equations estimated for the Saudis in order to get the true value instead of using Moyer's chart.
Sexual and racial diamorphisms in tooth size ratio between different races have long been established. ${ }^{23,24,25}$ As a result, multiple regression equations were estimated which include the sex factor. The results in males showed the $75 \%$ confidence level is the accurate determinant for the prediction of the maxillary tooth width of the cuspids and bicuspids. However, it seems no single confidence level works for females. It appears $65 \%$ is the relevant level of confidence for the sum of mandibular incisors with small values $(19.5 \mathrm{~mm}$ $-21.5 \mathrm{~mm}$ ), whereasfor large values the $75 \%$ level is the more accurate level. Further, the results in males exhibit the $65 \%$ confidence level is the accurate determinant for the prediction of the mandibular tooth width of the cuspids and bicuspids. As with the case of the maxillary teeth, there are two levels for females in the prediction of mandibular tooth width of the cuspids and bicuspids. For small values $(19.5 \mathrm{~mm}-22.5 \mathrm{~mm})$ the $65 \%$ is the accurate determinant, whereas for higher values the $75 \%$ is the accurate determinant. However in the Al-Khadra study, the sex factor was not investigated.

The result of the present study exhibited the Tanaka and Johnston prediction equations overestimate the size of the width of the cuspids and 
bicuspids in the Saudi sample. This finding is in agreement with the result obtained by Al-Khadra.

The results of the current study indicate methods relevant to races of European descent may not be applicable to other races; however, it is difficult to draw a firm conclusion due to the small sample size. Hence, it can be suggested for Saudis, the prediction equations (i) to (vi) may be used by the orthodontist as well as the pedodontist in the diagnosis and treatment plan of cases in the mixed dentition stage. The results of the current investigation support the need for future studies using a large representative sample from different parts of Saudi Arabia. This will help in establishing prediction tables for the Saudi population instead of using the well-known Moyer's prediction tables.

\section{Conclusion}

1. The $50 \%$ level was a more accurate determinant of the cuspids and bicuspids than the commonly used $75 \%$ level when both sexes are combined.

2. The multiple regression equations revealed in males the $75 \%$ confidence level is the accurate determinant for the prediction of the maxillary tooth width of the cuspids and bicuspids, whereas the $65 \%$ confidence level is the accurate determinant for the prediction of the mandibular tooth width.

3. No single confidence level works for females. It appears $65 \%$ is the accurate level of confidence for the sum of all values for maxillary and mandibular tooth width of the cuspids and bicuspids, whereas for large values the $75 \%$ level is the accurate level. ${ }^{2}$

\section{References}

1. Saatci P, Yukay F. The effect of premolar extraction on tooth-size discrepancy. Am J Orthod 111: 428-34, 1997.

2. Moyers RE. Handbook of Orthodontics. 3rd edition Chicago. London. Year book medical Publishers, Page no. 352, 1983.

3. Proffit WR, Fields HW, Ackerman JL, et. al. Contemporary Orthodontics. (Second Ed.) Mosby - Year book, Inc, Page 158, 1993.

4. Moorrees CFA. The dentition of the growing child a longitudinal study of dental development between 3 and 18 years age. Cambridge, Mass: Harvard University Press, Pages: 87-110, 230, 1959.

5. Hunter WS, Priest WR. Errors and discrepancies in measurement. J Dent Res 39: 405- 414, 1960.

6. Merz ML, Isaacson RJ, Germane N, et. al. Tooth diameter and arch perimeter in black and white population. Am J Orthod 100: 53-58, 1991.

7. Lundström A. Size of the teeth and jaw in the twins. Br Dent J 117: 321-326, 1964.

8. Hashim HA, Murshid Z. Mesiodistal tooth width in a Saudi population: A preliminary report. Saudi Dent J 5: 68-72, 1993.

9. Garn SM, Lewis AB, Kerewsky RS. X-Linked inheritance of tooth size. J Dent Res 44: 439 - 441, 1965 a.

10. Towsend GC, Brown T. Inheritance of tooth size in Australian aborigines. Am J Phys Anthropol 48: 305- 331, $1978 \mathrm{~b}$.

11. Hixon EH, Oldfather RE. Estimation of the sizes of unerupted cuspid and bicusipd teeth. Angle Orthod 28:236-240, 1958.

12. Tanaka MM, Johnston LE. The prediction of the size of un-erupted canine and prwemolars in a contemporary orthodontic population. J Am Dent Assoc 88:798-801, 1974.

13. Staley RN, O'Gorman TW, Hoag JF, et. al. Prediction of the widths of un-erupted canines and premolars. J Am Dent Assoc 108:185-190, 1984.

14. Al-Khadra BH. Prediction of the size of un-erupted canines and premolars in a Saudi Arab population. Am J Orthod Dentofac Orthop 104:369-372, 1993.

15. Dahlberg A. Statistical methods for medical and biological students. New York Interscience Publications, 1940.

16. Bolton WA. Thesis for master degree. University of Washington, Seattle. U.S.A. 1952.

17. Rudolph DJ, Dominguez PD, Ahn K, et. al. The use of tooth thickness in predicting intermaxillary tooth size discrepancies. Angle Orthod 68:133 - 138; discussion 39-40, 1998. 
18. Crosby DR, Alexander CG. The occurrence of tooth size discrepancies among different malocclusion groups. Am. J. Orthod Dentofacial Orthop. 95: 457 - 461, 1989.

19. Freeman JE Maskeroni AJ, Lorton L. Frequency of Bolton tooth size discrepancies among orthodontic patients. Am. J. Orthod Dentofacial Orthop.1996; 110: 24-27.

20. Fields HW. Orthodontic-restorative treatment for relative mandibular anterior excess tooth-size problems. Am. J. Orthod Dentofac Orthop 79: 176-183, 1981.

21. Bolton WA. The clinical application of tooth size analysis. Am J Orthod 48:504-529, 1962.

22. Tuverson DL. Anterior Interocclusal relations. Am J Orthod 78: 361-393, 1980.

23. Lavelle CLB. Maxillary and mandibular tooth size in different racial groups and in different occlusal categories. Am J Orthod Dentofac Orthop 61: 29-37, 1972.

24. Hashim HA, Murshid Z. Comparative study of Saudi and British populations on mesiodistal tooth width: A pilot study. Alexandria Dent J 17: 55 - 58, 1992.

25. Hashim HA, Murshid Z. 1993. Mesiodistal tooth width- A comparison between Saudi males and females, Part 1.Egyptian Dent. J 39:343 - 46, 1993.

\section{Acknowledgement}

The Authors would like to extend their appreciation to Dr. N. Khan and Dr. Zein AL-Abdin for their help with the statistical analysis.

\section{About the Authors}

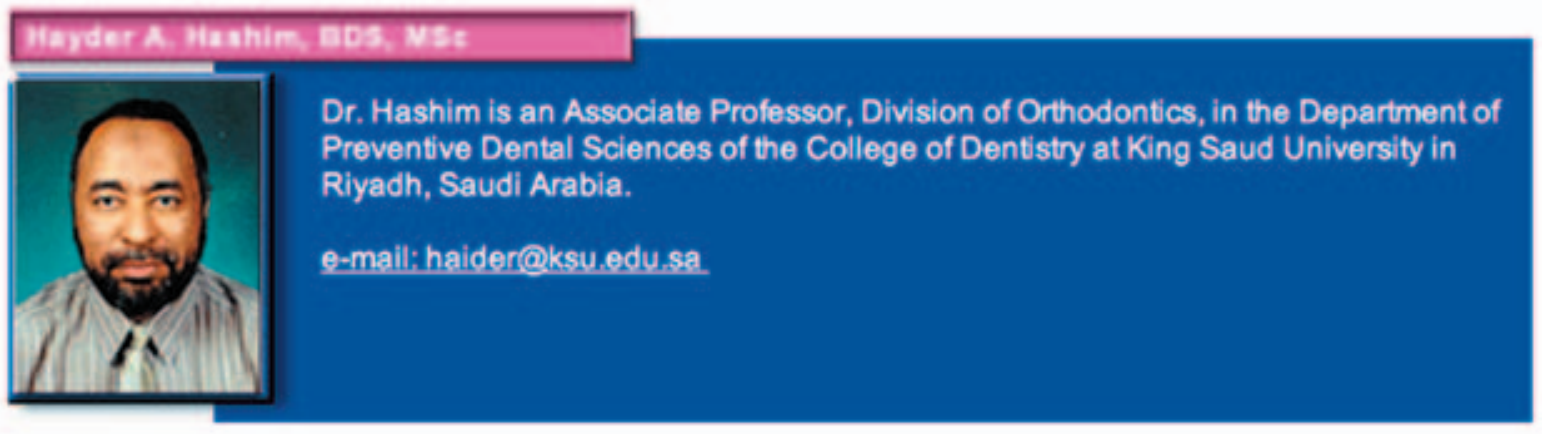

\section{Thakib A. AL Shaten, BDS, 48, PhD}

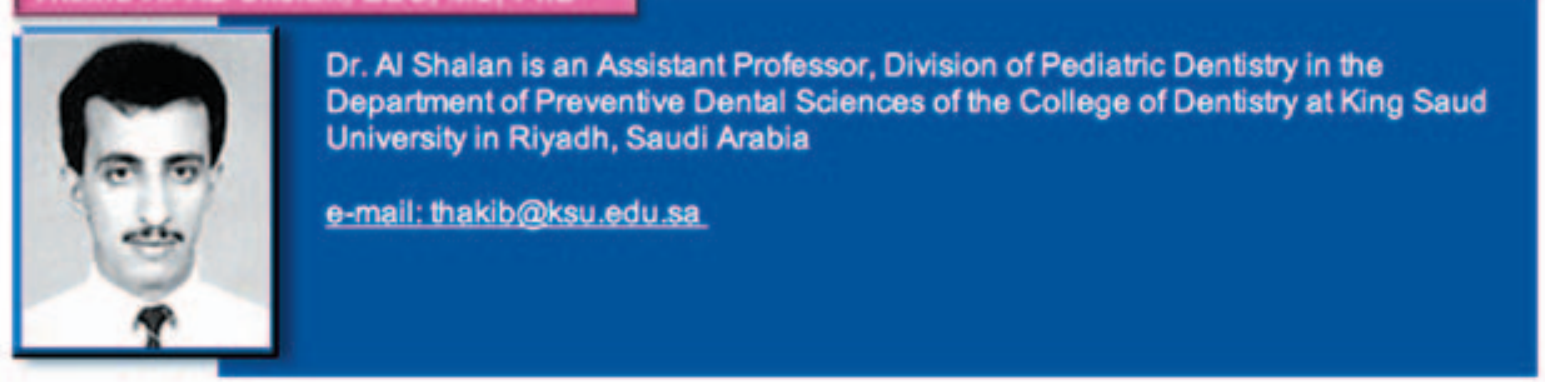

